\title{
Medico-Legal Aspects of Permanent Infirmities as a Sequel of Different Types of Injuries (A Retrospective Study in Assiut Governorate, Egypt)
}

\author{
Randa H. Abd El-Hady, Hayam Z. Thabet, Nagwa M. Ghandour'1, and Amr \\ Mohamed Mandor²
}

\author{
${ }^{1}$ Department of Forensic Medicine and Clinical Toxicology, Faculty of Medicine, Assiut University \\ ${ }^{2}$ Assiut Forensic Department of Ministry of Justice \\ Assiut, Egypt. \\ Corresponding author \\ Randa H. Abd El-Hady \\ E-mail: randa2004_25@hotmail.com
}

\begin{abstract}
Objective: To describe the percentage of permanent infirmities, the size of the problem in Assiut governorate during 2007 and 2008. Methods: A retrospective study of all cases of injuries lead to permanent infirmity from 1 January 2007 to 31 December 2008 through manual review of all files of Assiut Medico-legal department of Ministry of Justice. Results: The total cases of injuries with permanent infirmity were 144(7.28\%). The highest percent was in age group $>21-30(43.75 \%)$ followed by age group $>31-40$ years $(25.69 \%)$. Male cases represented $(92.36 \%)$ while females represented (7.64\%). Educated victims represented $(37.5 \%)$ where illiterate victims represented $(62.5 \%)$. The highest percent of victims were farmers $(68.75 \%)$. Most of victims were from rural areas $(93.05 \%)$. Blunt instruments were responsible for $(59.72 \%)$ followed by sharp instruments $(21.53 \%)$ and firearms $(18.75 \%)$. Extremities, represented $(38.19 \%)$ of cases, of which $(15.28 \%)$ due to nerve injuries while $(22.91 \%)$ were due to bone injuries. Head were the second site $(32.64 \%)$, followed by eye $(10.42 \%)$, abdomen $(8.33 \%)$ ear $(5.55 \%)$ and nose $(4.86 \%)$. The cause of injury was due to criminal assault $(81.94 \%)$, accidental $(18.06 \%)$, while there were no suicidal cases that ended in permanent infirmities.
\end{abstract}

Keywords Medico-legal, Forensic Medicine, disability, permanent infirmities, injuries, Assiut, Egypt

\section{Introduction}

$\mathrm{T}$ raumatic injury is recognized as a pandemic disease, and is a serious and growing global health issue. Worldwide, an estimated 5 million people die each year as a consequence of trauma; a figure predicted to increase to 8.4 million by 2020(Hans et al.,2009).

For each death due to trauma there are more than ten other persons who are seriously injured and some of them are permanently disabled. It had been noticed a remarkable decrease in mortality in the twentieth century while the number of disabled had increased considerably (Paden and Hyder, 2002).

Permanent infirmity is essentially a legal as well as a medical concept. The medico legal physician must have some understanding of legal theories and practices behind compensation for injuries in order to reform this role for the safe of the patient and the public (Frederick et al., 2000).

Permanent infirmity (disability) is defined as a functional limitation or loss caused by a physical or mental impairment that restrict the ability of a person to perform the daily activities (Kearney and Pryor, 2004).

In addition to lives lost, there is a long-lasting burden on many survivors of serious injuries in terms of chronic pain, permanent physical and/or mental disability, impaired quality of life, and loss of productive work years. In the United States (US), the number of lost years secondary to trauma is greater than the sum of lost years caused by malignancy and cardiovascular disease (Collins, 1991). 


\section{Aim of the work}

This work was conducted to study:

1- The percentage of permanent infirmities and the size of the problem in Assiut governorate, Egypt during 2007, 2008.

2- The relation between permanent infirmities and:

a. Age and sex of the victims.

b. Educational level, occupation, residence of the victims.

c. The causative instruments, organs affected, and circumstances of the cases.

\section{Materials and methods}

\section{Subjects and data collection}

All cases of injuries leading to permanent infirmities from 1 January 2007 to 31 December 2008 were retrospectively studied through manual review of all files of Assiut Medico-legal department of Ministry of Justice Egypt. Ethical consideration was taken regarding the consent of the legal authorities and the confidentiality of the obtained data.

\section{Statistical analysis}

Permanent infirmity cases during the study period were calculated and the collected data were analyzed for evaluation of the relation between permanent infirmities and age, sex, education level, occupation, residence, causative instruments, organs affected, and circumstances of the cases, using SPSS program version 15 .

\section{Results}

The number of examined cases by Assiut Medico-legal Department of Ministry of Justice during the study period is mentioned in Table (1). From (1978) cases, injuries without infirmities were 1392 cases $(70.37 \%)$, followed by autopsy cases $442(22.35 \%)$ while injured cases with permanent infirmity represented 144 cases (7.28\%). Figure (1) demonstrates age distribution of cases of permanent infirmities. The highest percent was in age group $>21-30(43.75 \%)$ followed by age group $>31-40$ years $(25.69 \%)$. The least percent was in age group 0-10 (1.38\%).

Figure (2) shows sex distribution of permanent infirmity cases. It demonstrates that males were predominantly affected $(92.36 \%)$ than females (7.64\%).

Table (2) shows the education level of persons with permanent infirmity in the studied period, the most predominant victims were illiterate victims who represented (62.5\%). Figure (3) shows the occupation of victims of injury with permanent infirmities. The highest percent of victims were farmers $(68.75 \%)$ followed by manual workers $(20.83 \%)$. Residence of victims of injuries with permanent infirmities were shown in Table (3) .Most of victims were from rural areas 134 victims $(93.05 \%)$ while victims from urban area were 10 victims only $(6.95 \%)$.

The causative instruments of permanent infirmities in examined cases are shown in Table (4). Blunt instruments were responsible for 86 victims $(59.72 \%)$ followed by sharp instruments 31 victims $(21.53 \%)$ and firearms were used in 27 victims $(18.75 \%)$. Table (5) reveals the anatomical site of injury. Extremities, upper and lower limb represented $(38.19 \%)$ of cases, of which $(15.28 \%)$ were due to nerve injuries while (22.91\%) were due to bone injuries. Injuries in the head were the second site $(32.64 \%)$, followed by eye $(10.42 \%)$, abdomen $(8.33 \%)$ ear $(5.55 \%)$ and nose $(4.86 \%)$, while there were no cases of permanent infirmities due to chest injuries. Figure (4) shows the alleged circumstances in case of permanent infirmities. Criminal assaults lead to the highest cases of infirmities, 118 cases (81.94\%). Accidental injuries lead to infirmities in 26 cases $(18.06 \%)$, while there were no suicidal cases that ended in permanent infirmities. Table (6) shows the relation between the instrument and the site of infirmity. Head infirmities were caused by blunt instruments in $91.5 \%$ and firearms in $8.5 \%$ of cases. All nose and ear infirmities were cause by blunt instruments $(100 \%)$.

Table (1): Number of injury cases examined by Assiut Medico legal Department of Ministry of Justice during the years 2007 and 2008 .

\begin{tabular}{|l|c|c|}
\hline \multicolumn{1}{|c|}{ Cases } & No. & \% \\
\hline Autopsy & 442 & 22.35 \\
\hline Injuries without infirmities & 1392 & 70.37 \\
\hline Injuries with Infirmities & 144 & 7.28 \\
\hline Total & 1978 & $100 \%$ \\
\hline
\end{tabular}

Table (2): Distribution of cases of permanent infirmities according to education level in Assiut Medico-Legal Department of Ministry of Justice during the years 2007 and 2008.

\begin{tabular}{|l|c|c|}
\hline Education level & No. & \% \\
\hline Educated & 54 & 37.5 \\
\hline Illiterate & 90 & 62.5 \\
\hline Total & 144 & $100 \%$ \\
\hline
\end{tabular}


Table (3): Frequency distribution of cases of permanent infirmities according to residence in Assiut MedicoLegal Department of Ministry of Justice during the years 2007 and 2008.

\begin{tabular}{|l|c|c|}
\hline Residence & No. & \% \\
\hline Rural & 134 & 93.05 \\
\hline Urban & 10 & 6.95 \\
\hline Total & 144 & $100 \%$ \\
\hline
\end{tabular}

Table (4): Relationship between type of instrument and occurrence of permanent infirmity in cases examined in Assiut Medico-Legal Department of Ministry of Justice during the years 2007 and 2008.

\begin{tabular}{|l|c|c|}
\hline \multirow{2}{*}{ Type of instrument } & \multicolumn{2}{|c|}{ Permanent infirmity } \\
\cline { 2 - 3 } & No. & \% \\
\hline Blunt & 86 & 59.72 \\
\hline Sharp & 31 & 21.53 \\
\hline Firearms & 27 & 18.75 \\
\hline Total & 144 & $100 \%$ \\
\hline
\end{tabular}

Table (5): Anatomical site of injury in cases of permanent infirmities examined in Assiut Medico-Legal Department of Ministry of Justice during the years 2007 and 2008.

\begin{tabular}{|l|c|c|}
\hline \multirow{2}{*}{ Site of injury } & \multicolumn{2}{|c|}{ Permanent } \\
\cline { 2 - 3 } & No. & \% \\
\hline Head & 47 & 32.64 \\
\hline Chest & -- & 0.00 \\
\hline Abdomen & 12 & 8.33 \\
\hline Eye & 15 & 10.42 \\
\hline Ear & 8 & 5.55 \\
\hline Nose & 7 & 4.86 \\
\hline Extremities & 55 & 38.19 \\
Nerve & 22 & 15.28 \\
Bone & 33 & 22.91 \\
\hline Total & 144 & $100 \%$ \\
\hline
\end{tabular}

Table (6) Relation between type of instrument and anatomical site of injury in cases of permanent infirmities examined in Assiut Medico-Legal Department of Ministry of Justice during the years 2007 and 2008.

\begin{tabular}{|c|c|c|c|c|c|c|c|c|c|c|c|c|c|c|}
\hline \multirow{2}{*}{ Instrument } & \multicolumn{2}{|c|}{ Head } & \multicolumn{2}{|c|}{ Chest } & \multicolumn{2}{|c|}{ Abdomen } & \multicolumn{2}{|c|}{ Eye } & \multicolumn{2}{|c|}{ Ear } & \multicolumn{2}{|c|}{ Nose } & \multicolumn{2}{|c|}{ Extremities } \\
\hline & No. & $\%$ & No. & $\%$ & No. & $\%$ & No. & $\%$ & No. & $\%$ & No. & $\%$ & No. & $\%$ \\
\hline & 43 & 91.5 & - & - & - & - & 8 & 53.4 & 8 & 100 & 7 & 100 & 20 & 36.4 \\
\hline & - & - & - & - & 6 & 50 & 7 & 46.6 & - & - & - & - & 18 & 32,7 \\
\hline Firearm & 4 & 8.5 & - & - & 6 & 50 & - & - & - & - & - & - & 17 & 30.9 \\
\hline
\end{tabular}

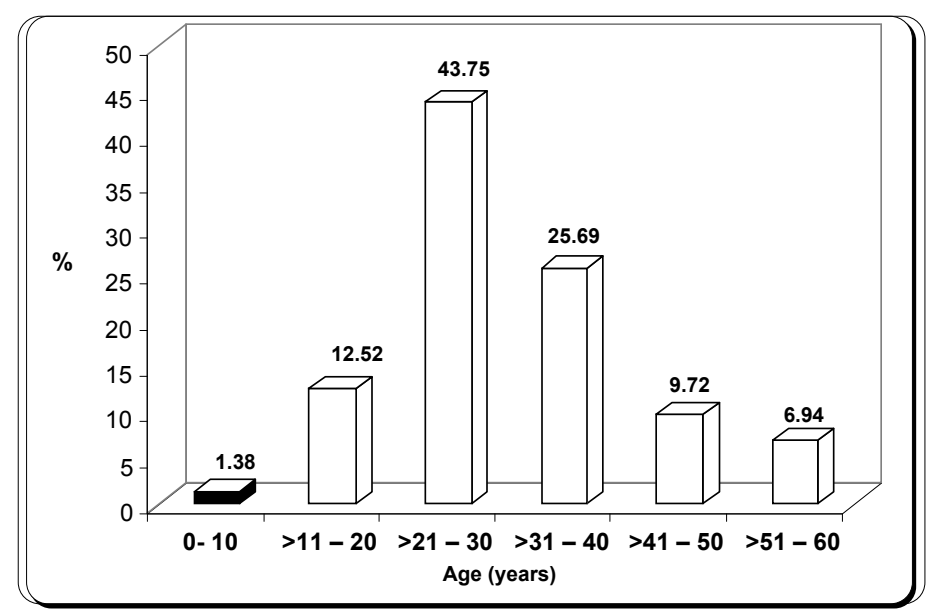

Figure (1): Age distribution of cases of permanent infirmities in Assiut Medico Legal Department of Ministry of Justice during the years 2007 and 2008. 


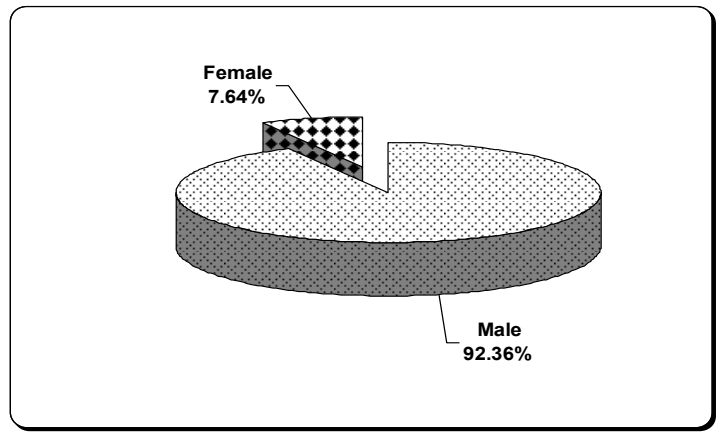

Figure (2): Sex distribution of cases of permanent infirmities in Assiut medico-legal department of ministry of Justice during the years 2007 and 2008.

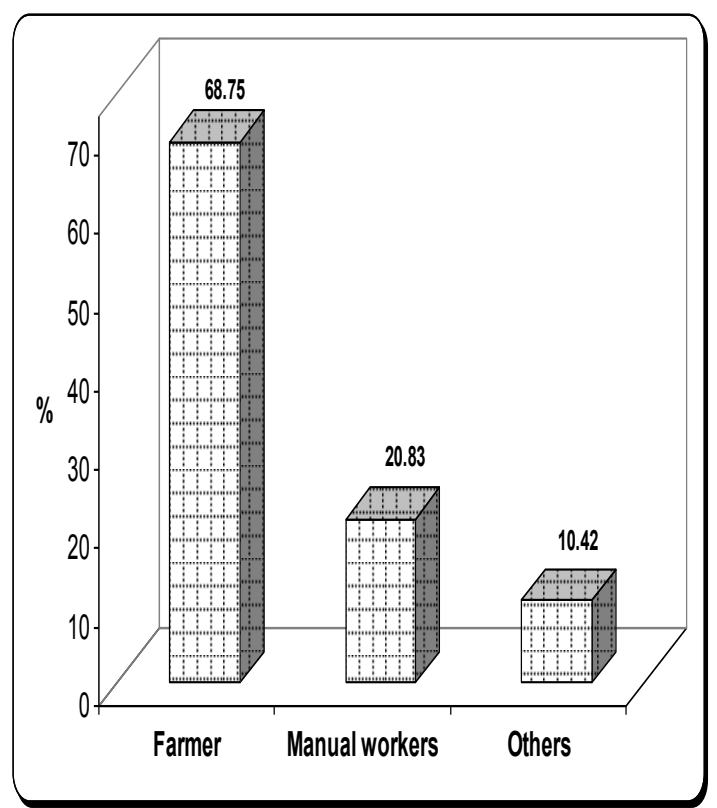

Figure (3): Frequency distribution of cases of permanent infirmity according to occupation in Assiut MedicoLegal Department of Ministry of Justice during the years 2007 and 2008.

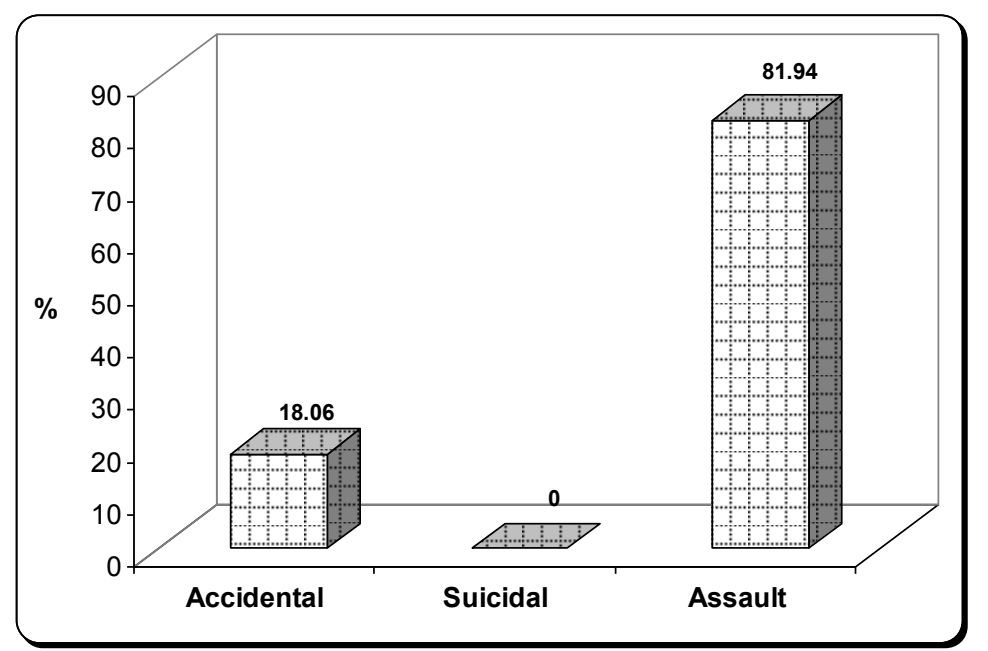

Figure (4): Permanent infirmities and alleged circumstances of injury in Assiut Medico-Legal Department of Ministry of Justice during the years 2007 and 2008.

\section{Discussion}

Injuries are a growing global public health problem. It killed over 5 million people in the year 2000 with many more being disabled (Paden and Hyder, 2002).
The Assiut province (one of the biggest Upper Egypt provinces) has a population of about 3444,967, according to 2006 statistics (Central Agency for Public Mobilization and Statistics Egypt, 2006). 
In the present study the number of injury cases without infirmities were 1392 cases $(70.37 \%)$, while injured cases with permanent infirmity represented 144 cases (7.28\%).

A retrospective study, done in Assiut on 1122 medical reports of victims of road traffic accidents in 1999 revealed how the problem of traffic accident is major and complicated. Death occurred in 158 cases while permanent infirmity represented $5 \%$ of cases who completed their treatment in a hospital while among those who escaped and discharged on request, the rate of infirmity was not known (Abdel Hady and Abdel Moneim, 2001). Also in a retrospective study of firearm injuries and fatalities examined by Assiut Medico-legal Department of Ministry of Justice in Year 2006, permanent infirmities represented about 9\% of all injured cases (Abdel Hady et al., 2008).

The National Center for Health Statistics report (Selected impairments due to injuries: United States1985-87), showed that large numbers of Americans were impaired by injury and that those impairments had a tremendous impact on the lives of individuals and the economy. It confirmed researches about the employment costs of impairments. During the mid-1980s, the 236 million people in the civilian, noninstitutionalized population had 61 million impairments. About $26 \%$ of these impairments were due to injuries. Of the 19 million impairments caused by injuries, about $12 \%$ resulted from injuries that occurred in the 12 months prior to the interview (Biddlecom and Collins, 1991).

The present study showed that the highest percent of permanent infirmities was in age groups $>21-30(43.75 \%)$ followed by age group $>31-40$ years $(25.69 \%)$. Males were predominant over females.

Trauma is primarily a disease of the young, exacting a high toll among an active and productive subgroup of the population. In young men, traumatic injury has been described as "epidemic" and more than $50 \%$ of deaths due to trauma occurs under the age of 45 (WHO health report 2003 and Fildes, 2004). Collins (1991), reported that adults aged 45 years and older had higher prevalence rates for all major categories of impairments due to injuries than younger adults.

Difference between men and women as regard impairments was also reported by Collins (1991). The prevalence rates for all types of selected impairments due to injuries, except for deformities and orthopedic impairments of the back were higher among men than women. These results were in agreement with the present result where males were predominant. Wasfy et al. (2009), reported in their study of ophthalmic medico legal cases in Upper Egypt that the majority of patients were males. This is most probably due to social habits keeping women sheltered in houses.
As regards the level of education the current study showed that $62.5 \%$ of cases of permanent infirmities were illiterate. These results were in agreement with the results of Zanaty (2005), where half $(50.2 \%)$ of permanent infirmity in injured cases referred to Menoufiya University Hospital were illiterate. This showed how the level of education and learning affect the aggression of injury and criminal behavior which lead to permanent infirmities.

The occupation of the victims seems to be a factor in the occurrence of injuries that lead to permanent infirmity.

In the present study the greatest percentage of permanent infirmity cases was among farmers $(68.75 \%)$ while manual workers represented $(20.83 \%)$. This could be explained by the fact that most of infirmities occurred in rural area where farmers are present in great number. These results are different from results of Zanaty (2005) in Menoufiya Governorate, where manual workers represented the greatest percentage of permanent infirmity cases.

There was significant percentage of permanent infirmity occurred in rural areas (93.05\%) this can be explained by presence of dangerous instruments that can cause severe injuries as heavy sticks, fass and firearm weapons without legal permission. This coincides with the results of Zanaty (2005), Sweilum (2002), and Nour El-Din (2004) in Menoufiya Governorate.

As regards type of the causative instrument used in occurrence of permanent infirmities in the present study, blunt instruments represented 59.72\% followed by sharp instruments (21.53\%) and firearm injuries $(18.75 \%)$. These results were in agreement with the results of ophthalmic medico-legal cases studied by Wasfy et al. (2009), in Upper Egypt where blunt instruments were the first $63.6 \%$ followed by sharp instruments $17.8 \%$ and firearm were the third in order $5.7 \%$.

In the present study the majority of infirmities were in extremities 55 cases $(38.19 \%) .33$ cases in bones and 22 cases in nerves. Head injury represented $(32.64 \%)$, and hearing impairment occurred in 5.55\% of cases.

Collins (1991), showed the types of impairments caused by injuries in United States (from 1985 to 1987) .Deformities or orthopedic impairments were the most prevalent, accounting for 13.6 million impairments or $71.8 \%$ of the impairments due to injuries. The majority of these deformities were in the back and extremities. Hearing impairments were the second most prevalent, adding up to 1.5 million conditions or $8.1 \%$ of the total.

In the present study the majority of permanent infirmity cases were homicidal attacks $(81.94 \%)$ while accidental cases were $(18.06 \%)$. This indicates the 
intent to cause damage and even death in homicidal attacks. These results were opposite to the results of McAllister et al. (1996) and Causey et al. (2008) where accidental cases were responsible for most of infirmity cases.

In conclusion, in the studied period and province, age group (21-30), males, illiterate victims, rural areas, blunt instruments and extremities are predominant. Also no permanent infirmities results from suicidal attempts.

\section{Recommendations}

- First aid measures and equipment must be available as early as possible at site of accidents or injuries to decrease the occurrence of infirmities.

- The medical staff in casualty department must do their efforts to treat the traumatized patient to avoid complication of simple injuries to change into dangerous injury with infirmity.

- Improvement of the different roads and use of safety measures as seat belt and head helmet in motorcycle to avoid severe injuries especially in head which occur in road traffic accidents.

- In Assiut region, homicidal attacks were contributing to a substantial number of cases of permanent infirmities while suicidal cases were uncommon. Trials to decrease the problem by strict police supervision of use of different types of weapons. Various law enforcing agencies have to make concentrated efforts and be more vigilant on this account in order to accomplish this goal.

\section{References}

Abdel- Hady R and Abdel Moneim W (2001): Medicolegal aspects of road traffic accidents in Assiut University Hospital. Egypt J. Forensic Sci. Appl. Toxicol. (1): 88-97.

Abdel-Hady R, Abdel Moneim W and Abdel Aal K (2008): Firearm injuries and fatalities. A preliminary study report in Assiut Governorate, Egypt in Year 2006. Zagazig J. of Forensic Med. and Toxicol . 6(1): 97-118.

Biddlecom A and Collins J (1991): Impairments due to injuries. Am J Public Health. 81(12):16701672.

Causey J, McFarren T and Nimlos J (2008): The AMA $6^{\text {th }}$ : Accelerating the demise of permanent disability in workers compensation. IAIABC J. 45: 49-64.

Centers for disease control (2004): Years of potential life lost before age 75 for selected causes of death, by sex, race and Hispanicorigin. United States, Health, selected years 19802004.Table 30, in http://www.cdc.gov/nchs/data/hus/hus06.pdf accessed in 2011.

Central Agency for Public Mobilization and Statistics Egypt, City Population (2006). In http://www.citypopulation.de/Egypt.html accessed in 2011.

Collins J (1991): Impairments due to injuries: United States, 1985-87. Vital Health Stat. 10(177): 150.

Fildes J (2004): National trauma data bank report, in http://www.facs.org/trauma/ntdb/docpub.html accessed in 2011.

Frederick B, Orzel M, Brown S et al., (2000): An evaluation of the effectiveness of the injuries minimization program for schools (IMPS). Inj. Prev. 6:92-5.

Hans-Christoph P, Edmund N, Saxon A et al., (2009): Cost-Drivers in Acute Treatment of Severe Trauma in Europe: A Systematic Review of Literature. Eur J Trauma Emerg Surg. 35:616.

Kearney P and Pryor J (2004): The international classification of functioning, disability and health (ICF) and nursing . J. of advanced nursing. 46(2): 162-170.

McAllister R, Gilbert S, Calder J et al., (1996): The epidemiology and management of upper limb peripheral nerve injuries in modern practice. Brit J. Hand Surg. 21: 4-13.

Nour El-Din F (2004): Medico-legal study on Head Injury and its Outcome in Menoufiya Governorate. Thesis for MD. Menoufiya University, Faculty of Medicine.

Paden M and Hyder A (2002): Road traffic injuries are a global public health problem. B.M.J. 324(7346): 1153.

Sweilum O (2002): Medico-legal aspects of cases of abdominal injury to Menoufiya University Hospital. Thesis for MD, Menoufiya University, Faculty of Medicine.

Wasfy I, Wasfy E, Aly T, et al., (2009): Ophthalmic medicolgal cases in Upper Egypt. Int Arch Med.2: 1-6.

WHO (2003): The world health report, shaping the future, Geneva, cited in http://www.who.int/whr/2003/en/whr03 en.pd $\mathrm{f}$ accessed in 2011.

Zanaty A (2005): Medico-legal study of permanent infirmity in injured cases referred to Menoufiya University Hospital. Thesis for MD. Degree in forensic medicine and clinical toxicology. 


\section{الملخص العربي

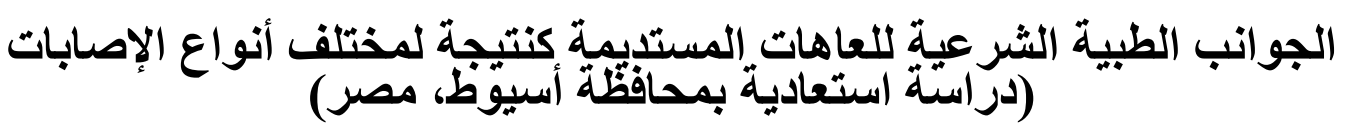

رندة حسين عبد الهادي وهيام زكريا ثابت و نجوى محمود غندور ${ }^{1}$ عمرو محمد مندور2

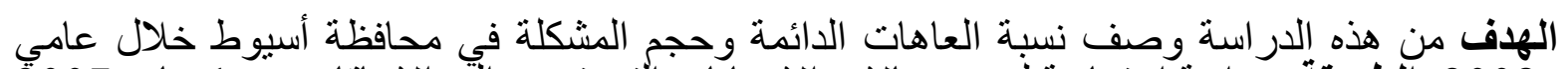

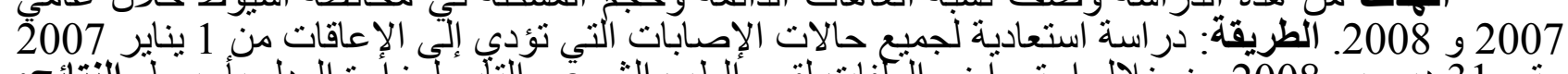

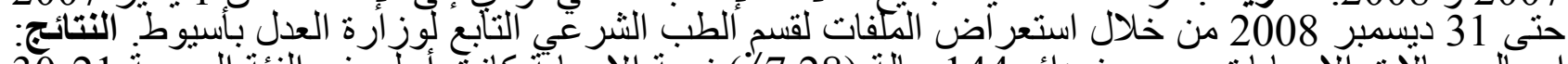

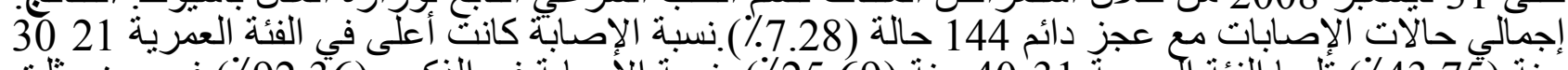

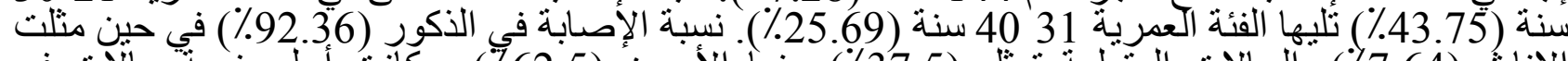

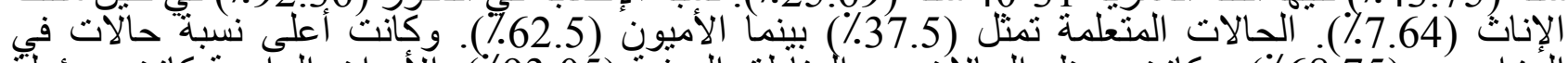

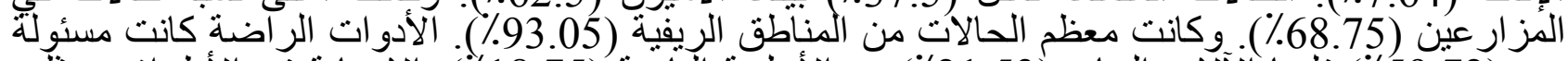

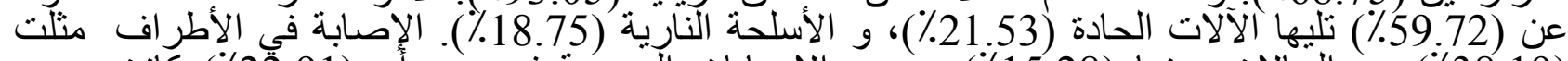

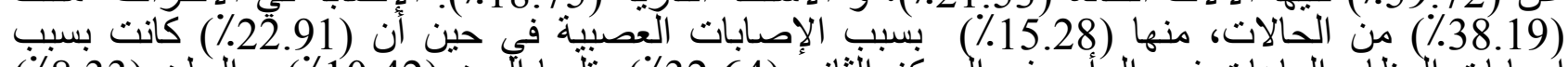

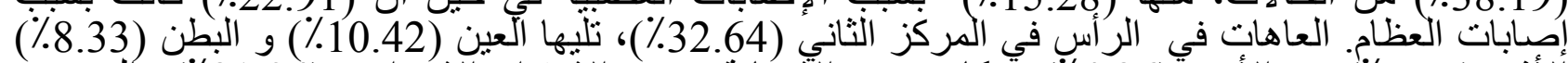

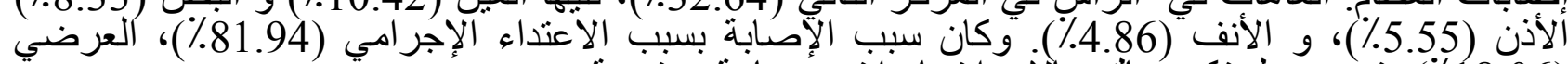

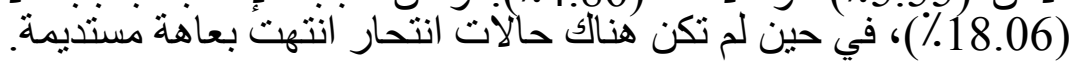

